\title{
The costs of hospital closure: reproviding services for the residents of Darenth Park Hospital
}

\author{
HowARD GlenNERSTER, Professor of Social Administration, London School of \\ Economics, Houghton Street, London WC2
}

There has been little economic evaluation of the costs of closing long-stay institutions. Studies that have been undertaken have rarely had the opportunity to study the before and after effects of complete closure. Most attention has focused on the mentally ill not the mentally handicapped. This study followed a sample of residents leaving Darenth Park Hospital which was closed in 1988.

\section{Background to the closure}

Darenth Park was one of the oldest institutions in England built specifically for people with a mental handicap. It began as "Darenth School" for 500 children in 1878. It soon found itself unable to place the children back into the community and only ten years after it was founded it was accommodating 1,000 adults and children. The National Health Service took over responsibility in 1948 . At one time there were over 2,000 residents on the site. The hospital served the whole of South East London, Kent and parts of Sussex. There were more than $\mathbf{4 0}$ wards, ten containing more than 50 residents. In January 1973 it was agreed to work towards closure. A long and complex process followed which is analysed in a forthcoming study (Korman \& Glennerster, 1990). The hospital did finally close in August 1988. Alternative facilities had been provided for all the residents except a few who left in the early years of their own accord. In 1978-79 there were 1,138 residents in Darenth. The plans for alternative provision date from the early 1970 s and were continuously revised until shortly before the hospital closed. Districts to whom residents were returning varied in their approach and philosophy. Examining the successive plans is rather like looking at a geological map showing layers that represent changing attitudes to the care of mentally handicapped people. In the early years an old hospital was converted to provide for 120 people who had been looked after in Darenth Park. Subsequently residential homes for 80 and then 40 people were designed. In the end most of the residents were rehoused in hostels, residential centres and most recently staffed group homes administered by local housing associations (for details see Korman \& Glennerster, 1990 - Table 1-3). Two hostels were converted properties. These were perhaps the most institutional. More informal were the residential centres, the designs for which became more and more like ordinary housing. The oldest has four buildings with 20 places in each. There are two, three and single person bedrooms, with shared kitchens, domestic staff and a central laundry. The other centres consist of separate houses or bungalows, with single or double bedrooms. Each has a housekeeper, cleaning staff and six to eight residents. Living room space is crowded, especially where there are wheelchairs. Day Centre facilities are attached. The group homes vary in size. Some accommodate two and some as many as eight residents. Most made use of existing housing stock. Because, as we shall see, these homes were able to attract non-NHS funds the staffing levels were more generous. Eight staff for four residents was not unusual. In some homes catering for residents with difficult or challenging behaviour, staffing ratios were as high as three staff to one resident or in one case five staff to one resident. At the other extreme there were five staff to seven residents. Local day centres and other facilities such as swimming pools were used where they existed. The impact on the residents and their adjustment to their new accommodation is being studied by Lorna Wing (Wing, 1989).

Our concern in this paper is to present an economic appraisal of the cost of alternative facilities that have been provided, and to compare that with the cost of the hospital care the residents used to receive.

\section{The study}

A sample of 100 residents was drawn, stratified to include the range of facilities opened since 1983. Full details of 93 residents were obtained. Care managers were interviewed to find out what facilities residents had used, what form of medication was involved, if any, what medical care, day care or other support they had received. Where community services were used we considered whether an additional marginal cost was incurred. The method and interview schedules closely correspond to those used by Knapp (1987) and Sheill \& Wright (1988). The measures of disability were those assigned to the residents by 
Lorna Wing in her parallel study (Wing, 1989). We collapsed her categories into four: socially impaired with behaviour problems socially impaired but amenable sociable with behaviour problems sociable and amenable

The task of calculating the economic costs of reprovision fell into five stages. First, the annual running costs were calculated for each of the facilities in which our sample were living. From the accounts of the NHS hostels and voluntary group homes it was possible to calculate an average cost per place. Accounts were available for 1987-88 in most cases, in others the costs were revalued to $1987-88$ prices. We were unable to obtain access to the accounts of the very few private institutions used.

Second, the individual questionnaires gave details of all the extra care the individual received and its extent, day care in half days, time spent as outpatients, as in-patients, with the GP, with an occupational therapist, chiropodist or any other specific extra facilities from a local authority. The costs of each were calculated based on the care staffs' estimate of the length of sessions involved. These must be treated with caution but, as we shall see, the costs are small compared to the average costs of the residential care facility. Finally, we include an item to cover the expenditure of residents on personal consumption. This was almost exclusively financed out of DHSS benefits and we have only included that element. It does not significantly affect the results and this item is shown separately. Taken together these figures give the total annual recurrent costs of care.

Third, it was necessary to calculate the annual capital cost of the new facilities for the same residents. These had all been built or converted in the last few years. This gave us essentially the current replacement cost of the new facilities, translated into $1987-88$ prices. As is standard practice, this total capital cost was expressed as an annual cost per resident. We assumed, following the then current Treasury and DHSS guidelines, a 60 year life for the buildings and a discount rate of $5 \%$. We also had to estimate the site value of land the NHS already owned. We erred on the low side, assuming a less than average London wide cost of housing land and that only half the site area could be used for development. Many of the sites were not ideal. The aim was to give a rough indication of the magnitudes involved.

Fourth, the cost of care in the old hospital had to be estimated. We took the total recurrent cost of the hospital when it was fully operative and when our sample of residents were still in Darenth in 1982. This was before any major movement out had occurred. An average running cost per resident was obtained and expressed in 1987-88 prices.
Fifth, it was necessary to produce some estimate of the capital cost of keeping the hospital and not using the land for some other purpose. We obtained a range of estimates of what it would have cost to replace the 100 year old hospital. That gave an estimate of the opportunity cost of capital involved in any decision to keep the hospital and the site. These capital costs were then annuitised in the same way as those for the community services. (A more detailed account of the methodology will be found in Korman \& Glennerster, 1990. The extent of estimation in the costing is such that the application of formal confidence limits would be inappropriate.) It was also of interest to know who paid for the new facilities. How far did the cost fall on the NHS and how far was the cost shifted onto other agencies? In each case we therefore looked not just at the expenditure side of the accounts in question but also at the income side. This enabled us to allocate the costs back to the funding agency. If, for example, the NHS met the costs of the care staff in a group home, that portion of the cost was assigned to the NHS. Where fees were charged and met by the DHSS that part of the costs was allocated to it. Where the rents were subsidised by a special hostel deficit grant from the Housing Corporation, the Department of the Environment were credited. We can therefore say not just what the total cost reprovision amounted to, but on which part of the public purse it fell.

\section{Findings}

Table I shows the average annual recurrent costs of the new facilities occupied by our sample. It can be seen that the older more institutionalised hostels run by the NHS had the lowest annual economic cost. The small group homes run by housing associations were able to draw on DHSS and Housing Corporation funds to cover part of the running expenses and these were more expensive. Space and staffing were more generous. The sums that covered medical expenditure and local authority services were relatively small and showed little variation between residents in the different kinds of facility. The overall dispersion of costs was very wide. The multiple and severely handicapped cost much more. In one case the annual cost of the special care arrangements amounted to over $£ 50,000$. There were 11 cases that cost more than $£ 30,000$ over a year. The categories of dependency we used do capture some of the cost differences but not as clearly as we had hoped. The socially impaired but amenable group were the least costly to provide for in both NHS and group homes. Those with behaviour problems were, as expected, the most costly and the cost differential seems to show up most in the group homes where staffing standards have to respond most directly. The social but amenable residents were able 
TABLE I

The average annual recurrent costs of reprovision (1987-88 prices)

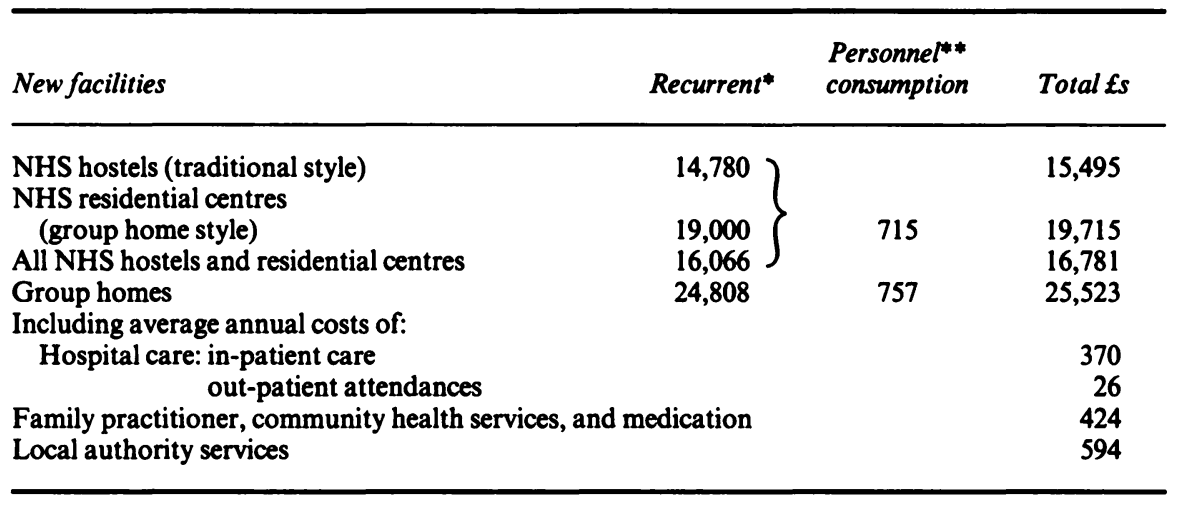

*including use of NHS hospital care and Community Services, GPs etc.

**DHSS financed only

TABLE II

Financing reprovision costs per annum (£ 1987-88)

\begin{tabular}{lcccc}
\hline & $\begin{array}{c}\text { NHS } \\
\text { facilities } \\
£\end{array}$ & $\begin{array}{c}\text { Group } \\
\text { homes } \\
\text { f }\end{array}$ & $\begin{array}{c}\text { NHS } \\
\text { facilities } \\
\%\end{array}$ & $\begin{array}{c}\text { Group } \\
\text { homes } \\
\%\end{array}$ \\
\hline $\begin{array}{l}\text { Recurrent costs met by: } \\
\text { NHS hospitals, FPC } \\
\text { and community health costs }\end{array}$ & 884 & 769 & 5.5 & 3.1 \\
$\begin{array}{l}\text { NHS long-term care costs } \\
\text { Local authority services }\end{array}$ & 14,665 & 15,310 & 91.3 & 61.7 \\
$\begin{array}{l}\text { DHSS payments } \\
\text { DoE housing costs }\end{array}$ & 517 & 655 & 3.2 & 2.6 \\
\hline Totals & - & 6,669 & - & 26.9 \\
\hline
\end{tabular}

to enjoy a wider range of activities outside the residence and this is reflected in their use of community resources.

By allocating these costs between funding agencies we derive Table II. This shows that the costs of residents living in NHS facilities were largely borne by the NHS. Where residents had moved to group homes and were drawing social security benefits and living in partly subsidised housing, the costs borne by the other agencies were higher. Group home residents' care was thus financed $65 \%$ by the NHS, $27 \%$ by the DHSS and in smaller parts by the other agencies, including $5.7 \%$ from the Department of the Environment for the housing element.

Table III shows the overall comparison with the cost of hospital care at Darenth Park. The costs of all movers were calculated using the costs derived from the sample and the costs of early movers to a small hospital were included to produce the weighted average cost. Capital costs and personal consumption financed by DHSS brought the total to about $£ 25,000$. The approximate estimate for the costs of care in the old hospital was $£ 16,500$.

\section{Comment}

Previous studies of community care have concluded that it was likely to prove less costly than hospital care. This study concludes the opposite. Most previous work has been concerned with the mentally ill not the mentally handicapped. In their case care is more continuous and in the more severe cases very intensive. We can only conclude that planners should expect the costs of new small scale facilities to be higher than the costs of hospital care. For anyone who is familiar with the kind of care that was pro- 
TABLE III

Average annual total costs of reprovision compared to the costs of care in Darenth Park (1987-88 prices $\mathrm{Es)}$

\begin{tabular}{lcccc}
\hline & Recurrent & $\begin{array}{c}\text { Personal } \\
\text { consumption }\end{array}$ & Capital & Total \\
\hline NHS hostels and centres & 16,066 & 715 & 3,500 & 20,281 \\
Group homes & 24,808 & 757 & 4,271 & 29,836 \\
$\begin{array}{l}\text { Total (weighted av.) } \\
\text { Average annual costs } \\
\text { of hospital care at }\end{array}$ & 20,715 & 740 & 3,800 & 25,225 \\
\begin{tabular}{l} 
Darenth Park \\
\hline
\end{tabular} & 12,452 & 429 & 3,500 & 16,500 \\
\hline
\end{tabular}

vided in old hospitals where staff were very difficult to recruit, it should come as no surprise that modern facilities and better staffing cost more money. The strange thing is that anyone ever believed otherwise.

These findings should be of particular importance to planners and practitioners in the light of the Government's proposals to change the basis of funding for community care anmounced in the recent White Paper (DoH, 1989). Social security funds will no longer be available to meet the costs of care in the community. Given the important part we have demonstrated it has played in reprovision, it will be critical to future plans that adequate alternative allocations are made to the local or health authorities seeking to make this policy a humane reality.

\section{References}

Department of Health Cmd 849 Caring for People: Community Care in the Next Decade and Beyond. London: HMSO.

KNaPP, M. (1987) The Cost Effectiveness of Psychiatric Reprovision Services. Discussion paper No. 533/2. Canterbury, PSSRU, University of Kent.

KORMAN, N. \& GlenNERster, H. (1990) Hospital Closure: A Political and Economic Study. Milton Keynes: Open University Press.

SHEILL, A. \& WRIGHT, K. (1988) Counting the Cost of Community Care: York University Centre for Health Economics.

WING, L. (1989) Hospital Closure and the Re-settlement of Residents. Aldershot: Gower.

\section{Cross-cultural psychiatric research: an anthropologist's view}

\section{INGA-BRITT KRAUSE, Social Anthropologist and Researcher, Academic Department of Psychiatry, University College and Middlesex School of Medicine, Wolfson Building, The Middlesex Hospital, London W1N 8AA}

A need for improved communication between the social sciences and psychiatry is being expressed from many quarters. Interest in social and cultural issues is not, of course, new to psychiatry, but collaboration between the two approaches has not always been easy. Recently one social science in particular has become popular with psychiatry. This is social anthropology, and many psychiatrists consider that the inclusion of anthropological data and methods, particularly in cross-cultural research, can be useful and informative to psychiatry. What then is the relationship between anthropology and psychiatry and what are the problems which professionals face in attempting interdisciplinary research? 